\title{
Nailfold capillary density is associated with the presence and severity of pulmonary arterial hypertension in systemic sclerosis
}

\author{
H M A Hofstee, ${ }^{1}$ A Vonk Noordegraaf, ${ }^{2}$ A E Voskuyl, ${ }^{3}$ B A C Dijkmans, ${ }^{3}$ P E Postmus, ${ }^{2}$ \\ Y M Smulders, ${ }^{1}$ E H Serné
}

\begin{abstract}
- An appendix is published online only at http://ard.bmj. com/content/vol68/issue2

${ }^{1}$ Department of Internal Medicine, VU University Medical Centre, Amsterdam, The Netherlands; ${ }^{2}$ Department of Pulmonary Medicine, VU University Medical Centre, Amsterdam, The Netherlands; ${ }^{3}$ Department of Rheumatology, VU University Medical Centre, Amsterdam, The Netherlands

Correspondence to:

H M A Hofstee, MD,

Department of Internal Medicine, VU University Medical Centre, De Boelelaan 1117, 1081 HV, Amsterdam, The Netherlands; hma.hofstee@ vumc.nl
\end{abstract}

Accepted 16 March 2008 Published Online First 28 March 2008

\section{ABSTRACT}

Objective: The aim of this study was to investigate whether there are differences in capillary nailfold changes in patients with systemic sclerosis (SSc) with and without pulmonary arterial hypertension (PAH), and whether these changes are associated with PAH severity and disease specificity.

Methods: Capillary density and loop dimensions were studied in 21 healthy controls, 20 patients with idiopathic PAH (IPAH) and 40 patients with SSc. Of the 40 patients with SSc, 19 had no PAH (SSc-nonPAH) and 21 had PAH (SSc-PAH), of whom eight had $\mathrm{PAH}$ during exercise.

Results: Capillary density was lower in SSc-PAH compared with patients who had SSc-nonPAH $14.33 / \mathrm{mm}$ vs $6.56 / \mathrm{mm}$ respectively, $p=0.001$ ), but loop dimensions were equal. In comparison with IPAH, patients with SScPAH had reduced capillary density $(4.33 / \mathrm{mm}$ vs $7.86 / \mathrm{mm}$, $\mathrm{p}<0.001$ ) and larger loop dimensions (total width $101.05 \mu \mathrm{m}$ vs $44.43 \mu \mathrm{m}, \mathrm{p}<0.001)$. Capillary density in healthy controls $(9.87 / \mathrm{mm})$ was significantly higher when compared with SSc-nonPAH (6.56/mm), SSc-PAH (4.33/ $\mathrm{mm})$ and with IPAH $(7.86 / \mathrm{mm})$. No differences in capillary dimensions were present between healthy controls and IPAH.

Capillary density correlated with mean pulmonary arterial pressure (PAP) at rest in SSc-PAH at rest $(r=-0.58$, $p=0.039)$ and IPAH $(r=-0.67, p=0.001)$.

Conclusions: Reduction of nailfold capillary density, but not capillary loop dimensions is associated with PAH, and correlates with the severity of PAH in both SSc and IPAH. This suggests that either systemic microvascular changes play a part in the development of $\mathrm{PAH}$, or that $\mathrm{PAH}$ itself contributes to systemic microvascular changes.

Systemic sclerosis (SSc) represents the main connective tissue disease (CTD) associated with pulmonary arterial hypertension $(\mathrm{PAH}) .{ }^{1} \mathrm{PAH}$ complicates an estimated $12 \%$ of patients with $\mathrm{SSc}$, and is a leading cause of death in this disease. ${ }^{2}$ Microvascular dysfunction is considered to be a key element in the pathogenesis of SSc and its complications. ${ }^{3-5}$

The majority of patients with SSc display characteristic structural changes of the capillaries in the nailfold, consisting of reduction in the number of capillaries (capillary density), and widening of capillary loops. ${ }^{6-8}$ A number of studies suggest an association between systemic microvascular changes and organ involvement in SSc; ${ }^{9-11}$ nevertheless, it is not clear whether systemic microvascular changes in SSc are associated with the presence and severity of PAH.
Better knowledge of the association between nailfold capillary characteristics and PAH in SSc could be useful both for better understanding of the pathophysiology of SSc-associated $\mathrm{PAH}$, as well as for stratification of SSc patients in terms of PAH risk. Recent developments, including computer based nailfold video capillaroscopy systems, have improved the quantitative assessment of microcirculatory changes such as capillary density and loop dimensions. ${ }^{6}$

The aim of this study was to test the hypothesis that there are differences in capillary density and capillary dimensions between patients with SSc$\mathrm{PAH}$ and SSc-nonPAH, and that these changes are quantitatively correlated with pulmonary haemodynamic parameters. To test the hypothesis that these changes are SSc specific, a group of patients with idiopathic PAH (IPAH), as well as healthy controls were investigated. Computer-based panorama mosaic video capillaroscopy was used to display the nailfold capillaries.

\section{MATERIALS AND METHODS Subjects}

Between September 2006 and July 2007 consecutive eligible patients with SSc and IPAH were recruited from the rheumatology and pulmonology departments of this hospital. The healthy controls were mainly staff members of the hospital who volunteered to participate in the study. Because of the female preponderance in patients with SSc, only female controls were recruited. All patients with SSc fulfilled the American College of Rheumatology criteria for SSc and were subsequently divided into a limited (LcSSc) and a diffuse (DcSSc) cutaneous SSc group according to LeRoy et al. ${ }^{12}$ Patients with IPAH did not have the symptoms and signs of CTD and were tested negative for antinuclear antigen (ANA).

PAH was diagnosed according to the clinical classification of Venice $2003,{ }^{13}$ with PAH defined as a mean pulmonary artery pressure (PAP) of $>25 \mathrm{mmHg}$ at rest or $>30 \mathrm{mmHg}$ during exercise as determined by right heart catheterisation. Exclusion criteria for PAH in patients with SSc were: (1) patients with SSc with New York Heart Association (NYHA) class I dyspnoea, and no signs of PAH at echocardiography and exercise testing; and (2) patients with SSc with NYHA class II dyspnoea with normal pressures as determined by right heart catheterisation at rest and during exercise. All patients with $\mathrm{SSc}$ required a total lung capacity (TLC) of $>70 \%$ of predicted, and a 
$\mathrm{pO}_{2}$ of $>60 \mathrm{mmHg}$ at rest. Study protocols were approved by the local ethics committee.

\section{Exercise testing and right heart catheterisation}

Before right heart catheterisation, maximal exercise tolerance and peak oxygen uptake $\left(\mathrm{VO}_{2} \mathrm{max}\right)$ were assessed by an exercise test on a cycle ergometer. PAPs were taken during right heart catheterisation. Cardiac output was determined and pulmonary vascular resistance (PVR) was calculated as the ratio of mean PAP to cardiac output. Cardiac index is defined as the cardiac output divided by the body surface area. Haemodynamic measurements were obtained at baseline and, if at baseline mean PAP was less than $25 \mathrm{mmHg}$, while cycling (see the appendix for further details).

\section{Capillaroscopy}

Capillaroscopy and computerised mosaic of the nailfold was obtained as described previously. ${ }^{6}$ For this study, only images from digit 4 of the non-dominant hand were used. Image quality was scored as 'good' or 'moderate'. Cases in which only 'poor' quality images were available, precluding identification of capillary architecture, were excluded from this study (see the online-only appendix for further details). The investigator was blinded to patient diagnosis and laboratory results; all images were coded. Capillary density (number of loops per $\mathrm{mm}$ ) was calculated by computer from the manually marked loops in the terminal row. Mean apex, arterial, venous and total capillary widths of the three to five widest capillaries were measured. In the case of irregular dilated capillaries, maximal width was measured.

\section{Statistical analysis}

Capillary density and dimensions showed a normal distribution in all categories and are presented as the mean and standard deviations (SD). Data on the duration of Raynaud's phenomenon and the duration of SSc were positively skewed and are presented as geometric means and $95 \%$ confidence interval of the back-transformed data after log transformation was performed. Numerical means of two or more independent categories were analysed using the Student's t test or one-way ANOVA, respectively. Differences between the groups with respect to capillary density and loop dimensions, were analysed using analysis of variance with and without adjustment for age and multiple comparisons (Bonferroni). Categorical variables were analysed using the $\chi^{2}$ or Fisher's exact test when appropriate. Correlation between density and pulmonary haemodynamic parameters were described using Pearson's correlation coefficient. Statistical significance was set at $p<0.05$. Results were calculated using computer software (SPSS, version 15.0 for Windows; SPSS; Chicago, Illinois, USA).

\section{RESULTS}

\section{Characteristics of subjects}

In one patient with SSc-PAH and one with IPAH, image quality was poor and these patients were excluded from the analyses. Characteristics of the 21 healthy controls, 20 patients with IPAH, 19 with SSc-nonPAH and 21 with SSc-PAH are shown in table 1.

Of the 19 patients with SSc-nonPAH, 16 had NYHA class I and no signs of PAH at echocardiography and exercise testing, and three had NYHA class II with normal PAP. Of the 21 patients with SSc-PAH, 13 had SSc-PAH at rest, and eight had SSc-PAH during exercise. In 93\% (75 of 81) of the cases it was possible to study digit 4 of the non-dominant hand, digit 3 and 5 were examined in the remaining 2 and 4 cases, respectively. The healthy controls were significantly younger than patients with IPAH and SSc. Raynaud's phenomenon was present in 95\% (38 of 40) of the patients with SSc. One patient with IPAH was considered to have long-standing primary Raynaud's phenomenon, as ANA was negative and there were no other clinical symptoms and signs of a CTD.

Four patients with IPAH, three with SSc-PAH at rest, and all patients with SSc-PAH during exercise were without medical treatment for $\mathrm{PAH}$. The other patients with SSc-PAH at rest and IPAH used monotherapy or combinations of prostaglandin/ prostacyclin analogous, endothelin receptor antagonists, and phosphodiesterase-5 inhibitors. No differences in capillary density were present between treated and non treated patients with SSc-PAH (4.5 vs $3.9 / \mathrm{mm}, \mathrm{p}=0.61$ ) and IPAH (7.2 vs 7.9/ $\mathrm{mm}, \mathrm{p}=0.38)$, and did not differ between treatment modalities, although some treatment categories were small.

There were no striking differences between the patients with $\mathrm{SSc}-\mathrm{nonPAH}$ and SSc-PAH in time since clinical diagnosis of $\mathrm{SSc}$, type of SSc (LcSSc or DcSSc) or antibody testing (table 2).

Compared with patients with SSc-PAH, patients with SScnonPAH were less likely to have any sign of pulmonary fibrosis in the dorsobasal fields on a high resolution computed tomography scan $(p=0.002)$, or a diffusing capacity for cardiac output of less than $70 \%$ of predicted $(p=0.009)$. None of the patients with IPAH had signs of pulmonary fibrosis on a computed tomography scan.

\section{Capillary density and dimensions in healthy controls, patients with idiopathic pulmonary arterial hypertension and systemic sclerosis subgroups}

The main findings on capillary microscopy are reported in table 3. In comparison with healthy controls, patients with SSc had reduced capillary density (5.36 vs $9.87 / \mathrm{mm}, \mathrm{p}<0.001)$ and larger loop dimensions (total width $101.05 \mu \mathrm{m}$ vs $43.20 \mu \mathrm{m}$, $\mathrm{p}<0.001$ ). Capillary density was lower in patients with SScPAH compared with patients with SSc-nonPAH (4.33 vs 6.56/ $\mathrm{mm}$ respectively, $\mathrm{p}=0.001)$, but no difference in capillary density between SSc-PAH at rest or SSc-PAH during exercise could be detected. Loop dimensions were equal in SSc-nonPAH, $\mathrm{SSc}-\mathrm{PAH}$ at rest, and SSc-PAH during exercise. A reduction in capillary density was also observed in patients with IPAH compared with healthy controls (7.86 vs 9.87 respectively, $\mathrm{p}=0.009$ ), but no differences in loop dimensions were present between patients with IPAH and healthy controls. In comparison with patients with SSc-PAH, patients with IPAH had a higher capillary density $(7.86$ vs $4.33 / \mathrm{mm}, \mathrm{p}<0.001)$ and smaller loop dimensions $(44.43 \mu \mathrm{m}$ vs $109.24 \mu \mathrm{m}, \mathrm{p}<0.001)$. Age was significantly different between controls, patients with IPAH, and patients with SSc, but capillary density and loop dimensions were not age related $(r=0.097, p=0.68$ for capillary density and age). Analysis of differences in capillary density and loop dimensions between groups with and without adjustment for age yielded similar results.

\section{Exercise testing and pulmonary haemodynamic parameters}

Exercise performances and haemodynamic parameters of patients with IPAH and SSc-PAH at rest were, as expected, worse than that of patients with SSc-PAH during exercise as measured by the cardiac index, mean PAP, PVR, 6 min walking test (6MWD), $\mathrm{VO}_{2}$ max, and maximal exercise tolerance (table 4). Exercise performances between patients with IPAH and SSc were not different. In comparison with SSc-PAH at 
Table 1 Characteristics of controls, patients with IPAH, SSc-nonPAH and SSc-PAH

\begin{tabular}{|c|c|c|c|c|c|}
\hline & \multirow[b]{2}{*}{$\begin{array}{l}\text { Controls } \\
(n=21)\end{array}$} & \multirow[b]{2}{*}{ IPAH $(n=20)$} & \multirow[b]{2}{*}{$\begin{array}{l}\text { SSc-nonPAH } \\
(n=19)\end{array}$} & \multicolumn{2}{|l|}{ SSc-PAH $(n=21)$} \\
\hline & & & & PAH rest $(n=13)$ & $\begin{array}{l}\text { PAH exercise } \\
(n=8)\end{array}$ \\
\hline Age, year (SD) & 37.7 (10.7) & $46.4(12.0)$ & $56.0(10.7)$ & $63.1(15.6)$ & $62.7(15.6)^{*}$ \\
\hline Female (\%) & $21(100)$ & $19(86)$ & $18(95)$ & $13(100)$ & $7(88) \dagger$ \\
\hline $\mathrm{RP}(\%)$ & 0 & $1(5)$ & $17(90)$ & $13(100)$ & $8(100) t$ \\
\hline $\begin{array}{l}\text { Duration of RP, year } \\
(95 \% \mathrm{Cl})\end{array}$ & NA & 27 (NA) & $6.3(4.0$ to 11.9$)$ & $15.3(10.9$ to 21.3$)$ & $6.6(2.7$ to 16.3$) \S$ \\
\hline $\begin{array}{l}\text { Good/moderate } \\
\text { image quality }\end{array}$ & $20 / 1$ & $19 / 1$ & $15 / 4$ & $12 / 1$ & $5 / 3 \dagger$ \\
\hline \multicolumn{6}{|c|}{$\begin{array}{l}\text { IPAH, idiopathic pulmonary arterial hypertension; NA, not applicable; PAH, pulmonary arterial hypertension; RP, Raynaud's } \\
\text { phenomenon; SSC, systemic sclerosis; SSc-nonPAH, SSc without PAH; SSc-PAH, SSc with PAH. } \\
\text { *Differences significant }(\mathrm{p}<0.05) \text { between categories. } \\
\text { †Differences not significant between categories. } \\
\text { +Difference not significant between SSc-non PAH and SSc-PAH. } \\
\text { §Difference significant }(\mathrm{p}<0.05) \text { between SSc-PAH at rest and SSc-nonPAH; difference not significant between SSc-PAH at rest } \\
\text { and SSc-PAH during exercise. }\end{array}$} \\
\hline
\end{tabular}

rest, patients with IPAH had a higher mean PAP (51.3 vs $39.2 \mathrm{mmHg}, \mathrm{p}=0.006)$, but no other differences in haemodynamic parameters were present. Capillaroscopy was performed after a median of 5.8 months (range -3 to 48 months) after right heart catheterisation. Time separation was shorter than 18 months in $90 \%$ of the patients.

\section{Correlation of capillary density with NYHA class and haemodynamic parameters}

A lower capillary density was associated with a higher NYHA class in patients with SSc $(p=0.042$ by ANOVA). Capillary density correlated with mean PAP at rest in SSc-PAH at rest $(\mathrm{r}=-0.58, \quad \mathrm{p}=0.039) \quad$ (fig 1$), \quad \mathrm{SSc}-\mathrm{PAH}$ during exercise $(r=-0.82, p=0.013)$, and IPAH $(r=-0.67, p=0.001)$ (fig 2$)$. Capillary density also correlated with PVR at rest in IPAH $(\mathrm{r}=-0.60, \mathrm{p}=0.005)$, and, although not significantly, in SScPAH at rest $(r=-0.50, p=0.08)$, but not in SSc-PAH during exercise $(r=-0.18, p=0.69)$. No correlation between capillary density and cardiac index or systemic vascular resistance was observed in the PAH groups.

\section{DISCUSSION}

Structural changes in the systemic microcirculation, consisting of reduction of capillary density and widening of capillary dimensions, are a hallmark of SSc. ${ }^{6-8}$ A novel finding of this study is that capillary density, but not capillary dimensions, differs between SSc-PAH and SSc-nonPAH, and correlates with pulmonary haemodynamic parameters. Interestingly, when compared with healthy controls, the same is true for patients with IPAH, a condition not known to be characterised by systemic microvascular changes. Our data suggest that widening of capillaries and capillary density reduction represents two different aspects of systemic microvascular involvement, ie, widening of capillaries is SSc specific, whereas reduction in capillary density is a marker of the presence and severity of PAH.

Few studies have investigated nailfold capillary patterns in patients with SSc-PAH, with only one study including patients with IPAH. Two studies used echocardiography and/or right heart catheterisation to confirm the diagnosis of PAH. One of these found a significant reduction of capillary density in eight patients with SSc with PAH in comparison with 12 patients with SSc without $\mathrm{PAH}^{14}$ No pulmonary haemodynamic parameters were reported in this study. The other study, using capillary density and qualitative scoring of nailfold patterns, found no differences in capillary patterns between eight patients with SSc-nonPAH and seven with SSc-PAH, but capillary density in these groups was not reported. ${ }^{15} \mathrm{~A}$ third study, using only right heart catheterisation to diagnose and exclude the diagnosis of $\mathrm{PAH}$, showed a significant difference in semi-quantitative scoring of nailfold patterns between

Table 2 Clinical, immunological and pulmonary findings in 40 patients with SSc

\begin{tabular}{|c|c|c|c|}
\hline & \multirow[b]{2}{*}{$\begin{array}{l}\text { SSc-nonPAH } \\
(\mathrm{n}=19)\end{array}$} & \multicolumn{2}{|l|}{ SSc-PAH $(n=21)$} \\
\hline & & PAH rest $(n=13)$ & $\begin{array}{l}\text { PAH exercise } \\
(\mathrm{n}=8)\end{array}$ \\
\hline Time since clinical diagnosis of SSc, year $(95 \% \mathrm{CI})$ & $3.7(1.3-10.7)$ & $2.8(1.6-5.0)$ & $4.2(1.6-27.8)^{*}$ \\
\hline Limited cutaneous SSc/diffuse cutaneous SSc & $17 / 2$ & $12 / 1$ & $7 / 1 \uparrow$ \\
\hline Antinuclear antibody (\%) & $17(90)$ & $13(100)$ & $7(88) \dagger$ \\
\hline Anticentromere antibody (\%) & $11(58)$ & $7(54)$ & $1(13) \dagger$ \\
\hline Anti-topoisomerase antibody (\%) & $2(11)$ & 0 & $3(38) \neq$ \\
\hline Anti-RNP antibody (\%) & 0 & $3(23)$ & $1(13) \dagger$ \\
\hline $\begin{array}{l}\text { Pulmonary fibrosis in the dorsobasal fields of the lungs } \\
\text { on HRCT thorax }(\%)\end{array}$ & $4(21)$ & $8(62)$ & $8(100)$ \\
\hline Total lung capacity \% of predicted (SD) & $96.8(8.4)$ & $91.1(10.3)$ & $91.8(13.9)^{*}$ \\
\hline Diffusing capacity for cardiac output $<70 \%$ of predicted (\%) & $8(42)$ & $12(86)$ & $6(75) \neq$ \\
\hline
\end{tabular}

HRCT, high-resolution computed tomography; PAH, pulmonary arterial hypertension; SSc, systemic sclerosis;

SSC-nonPAH, patients with SSc but no PAH; SSC-PAH, patients with SSc and PAH.

${ }^{*}$ Differences not significant between categories (ANOVA).

$\dagger$ Differences not significant between categories $\left(\chi^{2}\right)$.

fDifferences significant $(p<0.05)$ between categories $\left(\chi^{2}\right)$. 
Table 4 Cardiopulmonary findings in 41 patients with $\mathrm{PAH}$

\begin{tabular}{|c|c|c|c|}
\hline & \multirow[b]{2}{*}{$\begin{array}{l}\text { IPAH } \\
(n=20)\end{array}$} & \multicolumn{2}{|c|}{ SSc-PAH $(n=21)$} \\
\hline & & $\begin{array}{l}\text { PAH rest } \\
(\mathrm{n}=13)\end{array}$ & $\begin{array}{l}\text { PAH exercise } \\
(\mathrm{n}=8)\end{array}$ \\
\hline \multicolumn{4}{|l|}{$\begin{array}{l}\text { Cardiac index in } 1 / \text { min per } \mathrm{m}^{2} \text {, } \\
\text { mean (SD) }\end{array}$} \\
\hline at rest & $2.9(0.8)$ & $2.9(0.7)$ & $3.8(0.8)^{*}$ \\
\hline during exercise & & & $4.1(2.6)$ \\
\hline \multicolumn{4}{|l|}{ Mean PAP in mmHg, mean (SD) } \\
\hline at rest & $51.3(14.4) \dagger$ & $39.2(9.8) \dagger$ & $17.9(3.8)^{*}$ \\
\hline during exercise & & & $36.5(4.7)$ \\
\hline $\begin{array}{l}\text { Pulmonary vascular resistance at } \\
\text { rest in dyne } \mathrm{s} / \mathrm{cm}^{5} \text {, mean (SD) }\end{array}$ & $737.7(321.9)$ & $567.2(261.3)$ & $158.3(79.9)^{*}$ \\
\hline $6 \mathrm{MWD} \%$ of predicted, mean (SD) & $77.0(18.7)$ & $73.6(29.1)$ & $92.7(9.1) \$$ \\
\hline $\begin{array}{l}\mathrm{VO}_{2} \max \text { in } \mathrm{ml} / \mathrm{kg} \text { per min, } \\
\text { mean (SD) }\end{array}$ & $13.5(3.2)$ & $10.7(6.5)$ & $16.9(3.7)^{*}$ \\
\hline $\begin{array}{l}\text { Maximum exercise tolerance \% of } \\
\text { predicted, mean (SD) }\end{array}$ & $49.6(17.0)$ & $41.5(17.9)$ & $74.4(17.9)^{*}$ \\
\hline
\end{tabular}

6MWD, 6 min walking test; IPAH, idiopathic pulmonary arterial hypertension; PAH, pulmonary arterial hypertension; PAP, pulmonary arterial pressure; SSc, systemic sclerosis; SSC-PAH, patients with SSc and PAH.

${ }^{*}$ Differences significant $(p<0.05)$ between IPAH vs SSc-PAH exercise and between SSc-PAH rest vs SSc-PAH exercise.

$\dagger$ Differences significant $(p<0.05)$ between IPAH vs SSc-PAH rest. tDifferences not significant between categories (ANOVA).

SSc-nonPAH and SSc-PAH but, again, capillary density was not assessed in this study. ${ }^{16}$ Only one of these studies included patients with IPAH and reported no differences in capillary density and capillary patterns between 13 healthy controls and 37 patients with IPAH. ${ }^{15}$

In the present study, a reduction of capillary density was observed in both SSc-PAH and, albeit to a milder extent, in IPAH. However, the explanation for capillary density reduction may not be the same for both disorders. For SSc, it is generally presumed that structural changes in the systemic (micro)circulation precede changes in the pulmonary circulation, as systemic microvascular changes may precede SSc development by many years. ${ }^{15}$ Hence, nailfold capillary abnormalities might well reflect what is going on in the pulmonary circulation. This may not be true for all capillary abnormalities, because most patients with SSc demonstrate nailfold capillary abnormalities, whereas only a minority develop PAH. The present study

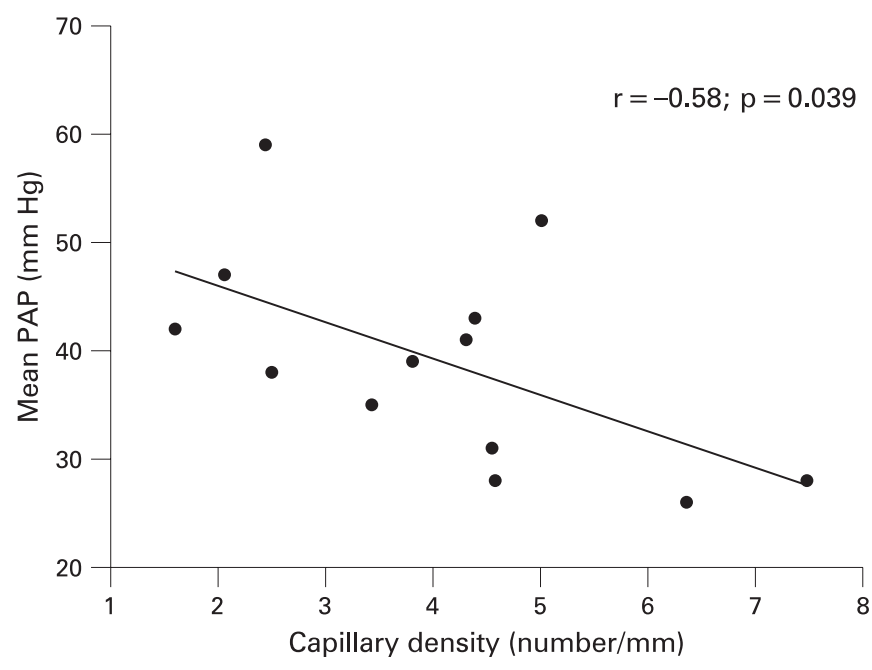

Figure 1 Correlation between capillary density and mean pulmonary arterial pressure (PAP) in patients with systemic sclerosis and pulmonary arterial hypertension at rest. 


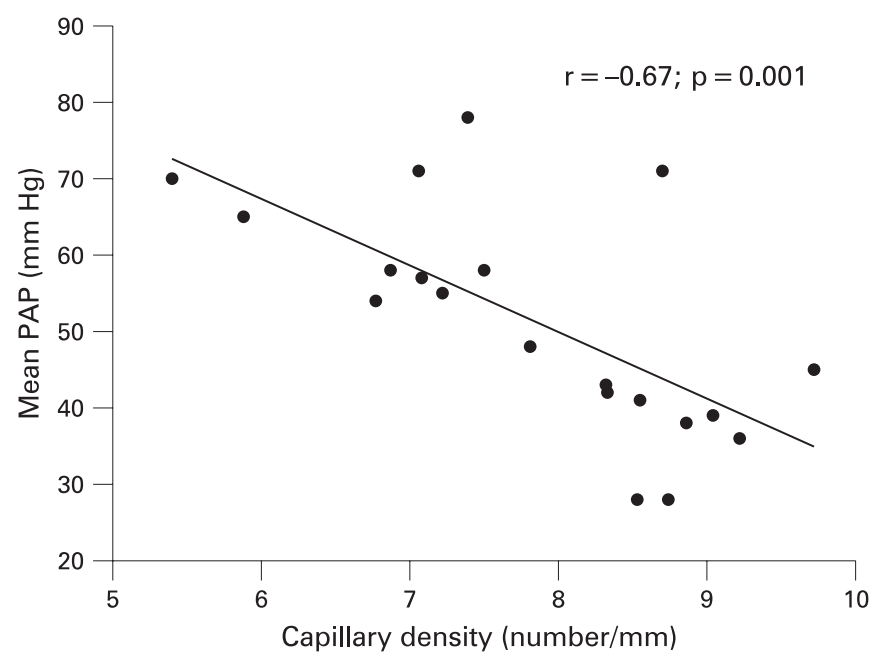

Figure 2 Correlation between capillary density and mean pulmonary arterial pressure (PAP) in idiopathic pulmonary arterial hypertension.

suggests that only capillary density is associated with the presence of PAH and is a marker of disease severity in SSc. In IPAH, disturbed structure or function of the systemic (micro)circulation is not considered to be a central feature. However, relatively mild abnormalities of systemic endothelial function (ie, brachial artery flow-mediated vasodilation) have recently been observed in IPAH, ${ }^{17}$ suggesting that IPAH may not be strictly limited to the pulmonary vascular bed. If indeed the systemic circulation is mildly affected in IPAH, this might explain the relatively mild degree of capillary density reduction seen in our patients. Therefore, another explanation for the more pronounced capillary reduction in SSc-PAH could be that PAH itself amplifies the already present reduction of capillary density in SSc. Finally, it is conceivable that, both in SSc-PAH and in IPAH, neurohumoral activation due to compromised cardiac function causes systemic microvascular dysfunction. However, this would be at odds with recent observations showing increased rather than decreased nailfold capillary density in patients with heart failure. ${ }^{18}$ In addition, we found no association between capillary density and cardiac index or systemic vascular resistance in our patients with PAH.

A computer-based panorama mosaic video capillaroscopy was used in this study to display a detailed image of a large part of the nailfold, that allows precise measurements of capillary density and loop dimensions. Furthermore, a diagnosis of PAH was confirmed by right heart catheterisation. However, although we feel that in patients with SSc with NYHA class I, and no signs of $\mathrm{PAH}$ at echocardiography and exercise testing, a diagnosis of $\mathrm{PAH}$ was reasonably excluded, right heart catheterisation remains the gold standard. Therefore, some subclinically PAH could not be fully excluded in this group. In addition, the group of patients with SSc-PAH during exercise was quite small.

From a pathophysiological viewpoint, our study sheds more light on the involvement of the microcirculation in SSc-PAH and IPAH, although subsequent research is needed to delineate whether the disturbances in the microcirculation are causal or consequential to PAH. From a clinical viewpoint, it is interesting to note that a simple, non-invasive tool, such as nailfold capillary microscopy is potentially capable of identifying patients with PAH.

Acknowledgements: The software to create the panorama mosaic images was received as a license agreement from the University of Manchester (UK). We would like to thank A L Herrick, MD, PhD (University of Manchester, Hope Hospital, Salford, UK), T Moore (Hope Hospital, Salford, UK) and P D Allen, PhD (University of Manchester, UK) for their kind support.

Competing interests: None.

\section{REFERENCES}

1. Coghlan JG, Handler C. Connective tissue associated pulmonary arterial hypertension. Lupus 2006;15:138-42.

2. Mukerjee D, St George D, Coleiro B, Knight C, Denton CP, Davar J, et al. Prevalence and outcome in systemic sclerosis associated pulmonary arterial hypertension: application of a registry approach. Ann Rheum Dis 2003;62:1088-93.

3. Herrick AL. Vascular function in systemic sclerosis. Curr Opin Rheumatol 2000;12:527-33.

4. Denton CP, Black CM. Targeted therapy comes of age in scleroderma. Trends Immunol 2005;26:596-602.

5. LeRoy EC. Systemic sclerosis. A vascular perspective. Rheum Dis Clin North Am 1996;22:675-94.

6. Anderson ME, Allen PD, Moore T, Hillier V, Taylor CJ, Herrick AL. Computerized nailfold video capillaroscopy - a new tool for assessment of Raynaud's phenomenon. J Rheumatol 2005;32:841-8.

7. Meli M, Gitzelmann G, Koppensteiner R, Amann-Vesti BR. Predictive value of nailfold capillaroscopy in patients with Raynaud's phenomenon. Clin Rheumatol 2006;25:153-8.

8. Cutolo M, Sulli A, Pizzorni C, Accardo S. Nailfold videocapillaroscopy assessment of microvascular damage in systemic sclerosis. J Rheumatol 2000;27:155-60.

9. Maricq HR, Spencer-Green G, LeRoy EC. Skin capillary abnormalities as indicators of organ involvement in scleroderma (systemic sclerosis), Raynaud's syndrome and dermatomyositis. Am J Med 1976;61:862-70.

10. Groen H, Wichers G, ter Borg EJ, van der Mark TW, Wouda AA, Kallenberg CG. Pulmonary diffusing capacity disturbances are related to nailfold capillary changes in patients with Raynaud's phenomenon with and without an underlying connective tissue disease. Am J Med 1990;89:34-41.

11. Caramaschi P, Canestrini S, Martinelli N, Volpe A, Pieropan S, Ferrari M, et al. Scleroderma patients nailfold videocapillaroscopic patterns are associated with disease subset and disease severity. Rheumatology (Oxford) 2007;46:1566-9.

12. LeRoy EC, Black C, Fleischmajer R, Jablonska S, Krieg T, Medsger TA Jr, et al. Scleroderma (systemic sclerosis): classification, subsets and pathogenesis. $J$ Rheumatol 1988;15:202-5.

13. Galie N, Torbicki A, Barst R, Dartevelle P, Haworth S, Higenbottam T, et al. Guidelines on diagnosis and treatment of pulmonary arterial hypertension. The Task Force on Diagnosis and Treatment of Pulmonary Arterial Hypertension of the European Society of Cardiology. Eur Heart J 2004;25:2243-78.

14. Ong YY, Nikoloutsopoulos T, Bond CP, Smith MD, Ahern MJ, Roberts-Thomson PJ. Decreased nailfold capillary density in limited scleroderma with pulmonary hypertension. Asian Pac J Allergy Immunol 1998;16:81-6.

15. Greidinger EL, Gaine SP, Wise RA, Boling C, Housten-Harris T, Wigley FM. Primary pulmonary hypertension is not associated with scleroderma-like changes in nailfold capillaries. Chest 2001;120:796-800.

16. Ohtsuka T, Hasegawa A, Nakano A, Yamakage A, Yamaguchi M, Miyachi Y. Nailfold capillary abnormality and pulmonary hypertension in systemic sclerosis. Int J Dermatol 1997;36:116-22.

17. Wolff B, Lodziewski S, Bollmann T, Opitz CF, Ewert R. Impaired peripheral endothelial function in severe idiopathic pulmonary hypertension correlates with the pulmonary vascular response to inhaled iloprost. Am Heart J 2007:153:1088-7.

18. Houben AJ, Beljaars JH, Hofstra L, Kroon AA, De Leeuw PW. Microvascular abnormalities in chronic heart failure: a cross-sectional analysis. Microcirculation 2003;10:471-8. 


\section{ARD}

\section{Nailfold capillary density is associated with the presence and severity of pulmonary arterial hypertension in systemic sclerosis}

H M A Hofstee, A Vonk Noordegraaf, A E Voskuyl, et al.

Ann Rheum Dis 2009 68: 191-195 originally published online March 28, 2008

doi: 10.1136/ard.2007.087353

Updated information and services can be found at:

http://ard.bmj.com/content/68/2/191.full.html

\begin{tabular}{|c|c|}
\hline \multirow[b]{2}{*}{ References } & These include: \\
\hline & $\begin{array}{l}\text { This article cites } 18 \text { articles, } 5 \text { of which can be accessed free at: } \\
\text { http://ard.bmj.com/content/68/2/191.full.html\#ref-list-1 }\end{array}$ \\
\hline \multirow[b]{2}{*}{$\begin{array}{l}\text { Email alerting } \\
\text { service }\end{array}$} & $\begin{array}{l}\text { Article cited in: } \\
\text { http://ard.bmj.com/content/68/2/191.full.html\#related-urls }\end{array}$ \\
\hline & $\begin{array}{l}\text { Receive free email alerts when new articles cite this article. Sign up in } \\
\text { the box at the top right corner of the online article. }\end{array}$ \\
\hline \multirow{2}{*}{$\begin{array}{l}\text { Topic } \\
\text { Collections }\end{array}$} & Articles on similar topics can be found in the following collections \\
\hline & Connective tissue disease (7718 articles) \\
\hline
\end{tabular}

Notes

To request permissions go to:

http://group.bmj.com/group/rights-licensing/permissions

To order reprints go to:

http://journals.bmj.com/cgi/reprintform

To subscribe to BMJ go to:

http://group.bmj.com/subscribe/ 